九州大学学術情報リポジトリ

Kyushu University Institutional Repository

\title{
Solubilities and diffusion coefficients of high boiling compounds in supercritical carbon dioxide
}

Higashi, Hidenori

Department of Chemical Engineering, Faculty of Engineering, Kyushu University

Iwai, Yoshio

Department of Chemical Engineering, Faculty of Engineering, Kyushu University

Arai, Yasuhiko

Department of Chemical Engineering, Faculty of Engineering, Kyushu University

http://hdl. handle. net/2324/12538

出版情報：Chemical Engineering Science. 56 (10)，pp.3027-3044，2001-05. Elsevier バージョン:

権利関係: (C) 2001 Elsevier Science Ltd. All rights reserved. 
A revised manuscript submitted to Chem. Eng. Sci.

Solubilities and diffusion coefficients of high boiling compounds in supercritical carbon dioxide - A review

Hidenori HIGASHI, Yoshio IWAI* and Yasuhiko ARAI

Department of Chemical Engineering, Faculty of Engineering, Kyushu University

6-10-1 Hakozaki Higashi-ku Fukuoka, 812-8581, JAPAN

E-mail : iwai@chem-eng.kyushu-u.ac.jp＿Tel\&Fax : +81-92-642-3496

Keywords: Solubility, Diffusion, Supercritical Fluid, Phase Equilibria, Equation of State, Thermodynamics

Text p.1-44, Figures 1-12, Tables 1-5 
A brief introduction of the data sources and the applications of correlation methods for the solubilities and diffusion coefficients of high-boiling compounds (mainly in solid state) in supercritical carbon dioxide are reviewed. Empirical equations, equations of state, solution models, and the Monte Carlo simulation for the calculation of solubilities in supercritical carbon dioxide are discussed. The application of empirical equation based on the Stokes-Einstein model, rough hard sphere theory, Schmidt number correlation, and molecular dynamics simulation for the calculation of diffusion coefficients in supercritical carbon dioxide at infinite dilution condition are reviewed. Further, the application of the Darken equation and the Leffler and Cullinan equation for the calculation of concentration dependence of diffusion coefficients in supercritical carbon dioxide are presented. 


\section{Introduction}

Recently, a large number of applications of supercritical fluid technology have been proposed for many processings of foods, pharamaceuticals, flavors, and chemicals. Among the proposed supercritical fluids, carbon dioxide is highly promising due to its near ambient critical temperature $\left(t_{\mathrm{C}}=31.0{ }^{\circ} \mathrm{C}\right)$, and its nontoxic and inflammable characteristics. A quantitative understanding of equilibrium and transport properties such as solubility and diffusion coefficient is very important for many of the proposed process designs. Fundamentals and applications of supercritical fluid technology have been described in several monographs, such as Paulaitis et al. (1983), Bruno and Ely (1991), King and List (1996), Smith and Hawthorne (1997), Clifford (1999), and ACS symposium series (Squires and Paulaitis, 1987; Charpentier and Sevenants, 1988; Johnston and Penninger, 1989; Hutchenson and Foster, 1995).

There are many ways to measure the solubilities and diffusion coefficients in supercritical fluids. Several reviews articles have been reported for experimental data and techniques for phase equilibrium measurement, e.g., Deiters and Schneider (1986), Fornari et al. (1990), Bartle et al. (1991b), Dohrn and Brunner (1995), Lucien and Foster (2000), and for diffusivity measurement, e.g., Liong et al. (1991a) and Suarez et al. (1998). Saito (1995) reviewed the research activities on supercritical fluid science and technology in Japan.

One of the main objectives of this paper is to review the data sources, such as previous reviews and the correlation methods for the solubilities and diffusion coefficients of high-boiling compounds in supercritical carbon dioxide including the recent studies of the authors and the Japanese workers.

\section{Available Data}




\subsection{Solubility}

Experimental techniques used to investigate multiphase equilibria can be classified by the method employed to determine compositions: analytical or direct sampling methods and synthetic or indirect methods, also called stoichiometric determinations. Direct sampling methods require composition analysis following the attainment of equilibrium and indirect methods involve an indirect determination of equilibrium composition without sampling. Most techniques used for measuring solubilities of solid components in supercritical fluids belong to the direct sampling methods and may be classified into four different categories (Bruno and Ely, 1991), namely (a) flow or dynamic methods and (b) static methods, (c) chromatographic methods, and (d) spectroscopic methods. The flow method is usually the simplest and most straightforward approach. Experimental methods for investigation of high pressure phase equilibria and available data have been detailed reviewed by Fornari et al. (1990) and Dohrn and Brunner (1995). Bartle et al. (1991b) reviewed the solubilities of solids and liquids of low volatility in supercritical carbon dioxide. Lucien and Foster (2000) reviewed the solubilities of solid mixtures in supercritical carbon dioxide and Erkey (2000) reviewed the extraction of metals from aqueous solutions by using supercritical carbon dioxide. Guclu-Ustundag and Temelli (2000) reviewed the solubilities of lipids in supercritical carbon dioxide. In recent works, the solubilities of antibiotics (Gordillo et al., 1999) and dyes (Sung and Shim, 1999; Lee et al., 1999; Wanger et al., 1999; Muthukumaran et al., 1999) in supercritical carbon dioxide have been reported and metal complex solubilities and metal extraction using chelating agents have been investigated using supercritical fluids (Özel et al., 2000). Mochizuki et al. (1999) reported perfluorocarboxylic acid counter ion enhanced the extraction of aqueous alkali 
metal ions with supercritical carbon dioxide. Kawakami et al. (2000) discussed the effect of counter cation on solubility of fluorocarbon surfactant in supercritical carbon dioxide.

Typical behavior of the solubility of a solid in supercritical carbon dioxide is shown in Figure 1. As shown in the figure, the solubilities are changed markedly by pressure at a given temperature. Further, the temperature dependence of solubilities differs in the low pressure (<12 MPa) and high pressure ( $>12 \mathrm{MPa}$ ) regions. On the other hand, solubility in ideal gas is decreased with pressure increase. It is noted that the solubility, in general, is smaller than that in liquid solvents, but that the solubility of a solid in a supercritical fluid is extremely sensitive to pressure. These features allow separations to be relatively simple for supercritical fluid solvents compared with liquid solvents. To increase the solid solubility in a supercritical fluid, sometimes entrainers (cosolvents) are added. In recent works, the solubilities of polychlorinated biphenyl (PCB) and behenic acid in supercritical carbon dioxide with cosolvents have been reported (Anitescu and Tavlarides, 1999; Guan et al., 1999).

\subsection{Diffusion Coefficient}

Experimental techniques, available data, and modeling of diffusivities in supercritical fluids were reviewed by Liong et al. (1991a) and Suarez et al. (1998). Suarez et al. (1998) listed the data of diffusion coefficients in supercritical fluids and illustrated correlation results. The experimental techniques used to determine diffusion coefficients in supercritical fluids may be classified into five different categories (Liong et al., 1991a), namely (a) solid dissolution method (pseudo-steady state and non-steady state), (b) capillary peak broadening method, (c) photon correlation spectroscopy, (d) nuclear magnetic resonance, (e) radioactive tracer response. The Taylor dispersion 
method (Taylor, 1953, 1954; Aris, 1956) is the most widely used technique to measure diffusion coefficients in supercritical fluids. According to that method, a narrow pulse of solute will broaden into a peak with the combined action of convection along the axis of the tube and molecular diffusion in the radial direction. Diffusion coefficients can be calculated by analytical description for the dispersion of solute pulse in pipelines. Many available diffusivity data are measured under the infinite dilution condition. Thus, several correlation equations for diffusion coefficients in supercritical fluids are generally based on condition at infinite dilution. Near the spinodal curve, there appears to be a decrease in the diffusion coefficient as shown by theoretical derivations and experimental measurements (Tsekhanskaya, 1971; Dysthe and Hafskjold, 1995; Nishiumi et al., 1996; Ago and Nishiumi, 1998). There may be consideration of concentration in the Taylor method as shown by Funazukuri et al. (2000a). The experimental diffusion coefficients for methane $+n$-decane system measured by Dysthe and Hafskjold (1995) are shown in Figure 2. As shown in this figure, the diffusion coefficients show large concentration dependence and an anomalous decrease near the critical concentration. In the recent works by Tuan et al. (1999a), a new technique for the measurement of diffusion coefficients is proposed. Concentration dependences of diffusion coefficients in supercritical carbon dioxide can be observed by the new technique and correlation methods for concentration dependence of diffusion coefficients in supercritical carbon dioxide have been discussed (Tuan et al., 1999c).

\section{Correlations}

\subsection{Solubility}

\subsubsection{Thermodynamic Basis}

For solid-gas equilibria, the equations of equilibrium which must be satisfied are of 
the form:

$$
f_{i}^{\mathrm{G}}=f_{i}^{\mathrm{S}}
$$

where $f_{i}^{\mathrm{G}}$ is the fugacity of component $i$ in the gas (supercritical fluid) phase and $f_{i}^{\mathrm{S}}$ is that in the solid phase.

The fugacity of solute in the supercritical phase is represented by the following expression.

$$
f_{2}{ }^{\mathrm{G}}=p \phi_{2}{ }^{\mathrm{G}} y_{2}
$$

where $p$ is the pressure, $\phi_{2}{ }^{\mathrm{G}}$ the fugacity coefficient, and $y_{2}$ the solubility (mole fraction) in a supercritical fluid. For phase equilibrium between a high-boiling compound and a supercritical fluid whose critical temperature is low, the following three assumptions commonly invoked: (1) the solid solute remains pure; (2) the molar volume of solid solute can be treated as a constant with respect to pressure; and (3) the saturated vapor of solid solute-vapor (pure) system behaves as an ideal gas. Using assumption (1), the fugacity of solute in the solid state, $f_{2}$, is equal to the pure solid fugacity, $f_{2}{ }^{0 \mathrm{~S}}$, and it can be derived as:

$$
f_{2}{ }^{\mathrm{S}}={f_{2}}{ }^{\mathrm{S}}={p_{2}}^{\mathrm{sat}}{\phi_{2}}^{0 \mathrm{G}} \exp \left(\int_{p_{2}{ }^{\mathrm{sat}}} \frac{v_{2}{ }^{\mathrm{S}}}{R T} d p\right)
$$

where $R$ is the gas constant, $T$ the temperature, $p_{2}{ }^{\text {sat }}$ the saturated vapor pressure, and $v_{2} \mathrm{~S}$ the solid-state molar volume of the solute. Based on assumptions (2) and (3), and the thermodynamic equilibrium condition, Eq.(1), the solubility can be calculated by the following equation.

$$
y_{2}=\frac{p_{2}{ }^{\text {sat }}}{p} \frac{\phi_{2}{ }^{\mathrm{OG}}}{{\phi_{2}}^{\mathrm{G}}} \exp \left(\int_{p_{2}{ }^{\mathrm{sat}}}^{p} \frac{v_{2}{ }^{\mathrm{S}}}{R T} d p\right)=\frac{p_{2}{ }^{\text {sat }}}{p} \frac{1}{{\phi_{2}}^{\mathrm{G}}} \exp \left[\frac{v_{2}{ }^{\mathrm{S}}\left(p-p_{2}{ }^{\text {sat }}\right)}{R T}\right]
$$


where the gas-phase fugacity coefficient of the pure solid, $\phi_{2}{ }^{0 \mathrm{G}}$, has been set equal to unity. The saturated vapor pressure and solid molar volume are physical properties of the pure solid solute and can be obtained from literature data or by using an appropriate correlation equation. Therefore, the solute solubility is primarily a function of solid solute pure compound physical properties, the system temperature and pressure, and the fugacity coefficient of the solid solute in the supercritical fluid.

\subsubsection{Empirical Equation}

By adopting the Leiden-type virial equation of state with second and third virial coefficients to evaluate the fugacity coefficient, $\phi_{2}{ }^{\mathrm{G}}$, in Eq.(4), the solubility can be derived as follows:

$\ln y_{2}=\ln \left(\frac{p_{2}{ }^{\text {sat }}}{R T}\right)+\frac{v_{2}{ }^{\mathrm{s}}\left(p-p_{2}{ }^{\mathrm{sat}}\right)}{R T}-\ln \rho_{1}-2 B_{12} \rho_{1}-(3 / 2) C_{112} \rho_{1}^{2}$

where $\rho_{1}$ is the density of a supercritical fluid, and $B_{12}$ and $C_{112}$ are the cross second and third virial coefficients, respectively. As shown in Eq.(5), the solubility depends on the density of the supercritical fluid and the interaction between solute and supercritical fluid indicated by the cross second and third virial coefficients. Quiram et al. (1994) applied the density series virial equation of state truncated at the third virial coefficient to evaluated for describing the fluid nonideality of systems of pure solids in equilibrium with near-critical carbon dioxide including systems with cosolvents.

Several empirical equations for the solubility in a supercritical fluid have been proposed as a function of density for a supercritical fluid. Schmitt and Reid (1985) proposed the following equation.

$\ln E=a \rho_{1}^{*}+b+c(T-d)$

where $E\left(=P y_{2} / p_{2}{ }^{\text {sat }}\right)$ is the enhancement factor, $\rho_{1}{ }^{*}\left(=\rho_{1} / \rho_{1 \mathrm{C}}\right)$ the reduced density of the 
supercritical fluid, and $a, b, c$ and $d$ are the empirical parameters. Figure 3 shows the relationship between the enhancement factor of naphthalene and the density of supercritical carbon dioxide. As shown in Figure 3, the enhancement factor increases linearly with the reduced density. The deviations at $308.2 \mathrm{~K}$ would belong to the reliability of equation of state which is used to calculate the density of supercritical fluids, because the temperature is very close to the critical temperature of carbon dioxide. However, the enhancement factor may increase more linearly when the density of mixture is adopted. This relationship between the enhancement factor and the reduced density can be converted to those between the solubility and the density of a supercritical fluid. Some other empirical equations are proposed as Eqs.(7)-(9).

$$
\begin{array}{ll}
\ln y_{2}=a \ln \rho_{1}+b & \text { Stahl et al. (1978) } \\
\ln y_{2}=a \delta_{1}^{2}+b \delta_{1}+c, \delta_{1}=\left(\delta_{1}^{\mathrm{L}} / \rho_{1}^{\mathrm{L}}\right) \rho_{1} & \text { Czubryt et al. (1970) } \\
y_{2}=\rho_{1}^{c} \exp (a / T+b) & \text { Chrastil (1982) }
\end{array}
$$

where $\delta_{1}$ is the solubility parameter of a supercritical fluid.

The Krischevskii parameter, $(\partial p / \partial x)_{T, v}^{\infty, C}$, can also be used to check the consistency of data obtained in different sets of experiments. The Krischevskii parameter is defined as the change in pressure that occurs when a solute is added to a solvent at its critical point, temperature and volume being kept constant. Furuya and Teja (2000) were calculated the Krischevskii parameters from measurements of the solubility of heavy n-alkanes in supercritical carbon dioxide. Mendez-Santiago and Teja $(1999,2000)$ have been investigated the consistency of solubility data for the design of extraction and separation equipments.

\subsubsection{Equation of State}


The thermodynamic definition of the fugacity coefficient is given by the following equation:

$\ln \phi_{2}{ }^{G}=\frac{1}{R T} \int_{V}^{\infty}\left[\left(\frac{\partial p}{\partial n_{i}}\right)_{T, V, n i \neq j}-\frac{R T}{V}\right] d V-\ln z$

where $z$ is the compressibility factor. Cubic equations of state such as Soave-Redlick-Kwong (SRK) equation (Soave, 1972) and Peng-Robinson (PR) equation (Peng and Robinson, 1976) are widely used to evaluate the fugacity coefficient. The cubic equation of state proposed by Yu et al. (1987a, b) is introduced here:

$$
p=\frac{R T}{v-b}-\frac{a}{v(v+c)+b(3 v+c)}
$$

where, $a, b$, and $c$ are parameters which can be determined from the critical properties and the acentric factors of the pure components. The equation of state is given by Eq.(11) and has been developed to represent the $p V T$ relationship with a good correlation in a wide range substances from low-boiling compounds (e.g., carbon dioxide) to high-boiling compounds (e.g., naphthalene). To apply the equation of state to a mixture, the following mixing and combining rules can be used:

$$
\begin{aligned}
& a=\sum \sum y_{i} y_{j} a_{i j}, a_{i j}=\left(1-k_{i j}\right)\left(a_{i} a_{j}\right)^{0.5} \\
& b=\sum \sum y_{i} y_{j} b_{i j}, \quad b_{i j}=\left(1-l_{i j}\right)\left(b_{i}+b_{j}\right) / 2 \\
& c=\sum \sum y_{i} y_{j} c_{i j}, \quad c_{i j}=\left(1-l_{i j}\right)\left(c_{i}+c_{j}\right) / 2
\end{aligned}
$$

where $k_{i j}$ and $l_{i j}$ denote the characteristic parameters between unlike molecules $i$ and $j$. Figure 4 shows correlation results for the solubilities of naphthalene and dimethylnaphthalene isomers in supercritical carbon dioxide. The physical properties and the values of the parameters used for the correlation are listed in Tables 1 and 2 . 
The calculated results show good agreement with the experimental results by adjusting the characteristic parameters. As the solubility is usually small, it is noted that the introduction of $l_{12}$ as well as $k_{12}$ is effective to give good correlations (Iwai et al., 1989). Eqs.(11)-(14) can also be adopted to correlate entrainer effects as shown in Figure 5. This figure shows the correlation results of entrainer effect on the solubilities for aciridine in supercritical carbon dioxide. The properties and the parameters are listed in Tables 1 and 2. The calculated results of entrainer effect on the solubilities show good agreement with the experimental data. Interaction parameters $k_{12}$ and $l_{12}$ are considered to be large values for complex and polar molecules. . Trabelsi et al. (1999) used the PR equation of state and equation for perturbed hard-sphere to estimate the solubilities of solids in dense carbon dioxide. Yamamoto et al. (2000) correlated solubilities and entrainer effects for fatty acids and higher alcohols in supercritical carbon dioxide using SRK equation of state with association model.

Equations of state such as the predictive Soave-Redlich-Kwong (PSRK) method (Holderbaum and Gmehling, 1991) or Peng-Robinson equation of state with the analytical solutions of group (PRASOG) method (Tochigi, 1995) can be used to calculate the solubility of solute in supercritical fluids by a molecular group contribution. Solubilities in supercritical fluids can be estimate by predicting the excess Gibbs free energy using group contribution methods. Tochigi et al. (1998) applied PRASOG to estimate the solubilities in supercritical carbon dioxide and indicated the applicability of PRASOG.

\subsubsection{Solution Model}

In the supercritical state, a fluid has a high density when compared with a gas. In fact, the density of a supercritical fluid is closer to that of a liquid than that of a gas. In 
theoretical treatments, the supercritical fluid phase can be treated approximately as an expanded liquid. This allows the phase equilibria between the solute and the supercritical fluid to be represented thermodynamically by solid-liquid equilibrium relations and conventional activity coefficients.

$$
f_{i}^{\mathrm{L}}=f_{i}^{\mathrm{S}}
$$

The fugacity of solute in the supercritical fluid phase and the solid phase can be represented by the following expressions, respectively.

$$
\begin{aligned}
& f_{2}{ }^{\mathrm{L}}=\gamma_{2}{ }^{\mathrm{L}} y_{2} f_{2}{ }^{\mathrm{OL}} \\
& f_{2}{ }^{\mathrm{S}}=\gamma_{2}{ }^{\mathrm{S}} x_{2} f_{2}{ }^{0 \mathrm{~S}}
\end{aligned}
$$

where $f_{2}{ }^{0 \mathrm{~L}}$ and $f_{2}{ }^{0 \mathrm{~S}}$ are the fugacities of pure solute, and $\gamma_{2}{ }^{\mathrm{L}}$ and $\gamma_{2}^{\mathrm{S}}$ denote the activity coefficients of solute in the expanded liquid phase (supercritical fluid phase) and the solid phase, respectively. When the solubility of supercritical fluid in solid phase is negligible ( $x_{2}=1$ and $\left.\gamma_{2}^{\mathrm{S}}=1\right)$ and the solubility in supercritical carbon dioxide can be assumed to be at infinite dilution condition, the solubility can be determined by the following equation as proposed by Kramer and Thodos (1988).

$$
y_{2}=\frac{1}{\gamma_{2}^{\infty}} \frac{f_{2}{ }^{0 \mathrm{~S}}}{f_{2}^{0 \mathrm{~L}}}
$$

where $\gamma_{2}^{\infty}$ is the activity coefficient of solute at infinite dilution in the expanded liquid (supercritical fluid phase). The ratio of the fugacities can be approximated by the next equation.

$$
\ln \frac{f_{2}{ }^{0 \mathrm{~S}}}{f_{2}{ }^{0 \mathrm{~L}}}=\frac{\Delta h_{2}{ }^{m}}{R T}\left(\frac{T}{T_{2}{ }^{m}}-1\right)
$$

where $T_{2}{ }^{\mathrm{m}}$ is the melting point of the solid and $\Delta h_{2}{ }^{\mathrm{m}}$ is the heat of fusion. The infinite 
dilution activity coefficients can be evaluated by using solution theory.

The regular solution model (Hildebrand et al., 1970) coupled with the Flory-Huggins theory (Flory, 1942) can be used to correlate solubilities in supercritical fluids. Further, the solution model can also be applied to correlate entrainer effects. The solubility in supercritical carbon dioxide at infinite dilution condition can be calculated by the following equation (Koga et al., 1996):

$$
\ln y_{2}=\frac{\Delta h_{2}^{\mathrm{m}}}{R T}\left(\frac{T}{T_{2}^{\mathrm{m}}}-1\right)-\frac{v_{2}}{R T}\left\{\left(\delta_{1}-\delta_{2}\right)^{2} \phi_{1}+\left(\delta_{2}-\delta_{3}\right)^{2} \phi_{3}-\left(\delta_{1}-\delta_{3}\right)^{2} \phi_{1} \phi_{3}\right\}-\ln \frac{\phi_{2}}{y_{2}}-1+\frac{\phi_{2}}{y_{2}}
$$

where 1, 2, 3 refer to the supercritical fluid, solute, and entrainer, respectively. The $v_{i}$ and $\delta_{i}$ are the molar volume and the solubility parameter of component $i$ in the supercritical fluid phase. For assumption of infinite dilution of solute, the volume fractions of component $i, \phi_{i}$, are denoted by Eqs.(21) and (22). By letting $\phi_{3}=0$, Eq.(20) can be applied to a binary system.

$$
\begin{aligned}
& \phi_{i}=\frac{y_{i} v_{i}}{y_{1} v_{1}+y_{3} v_{3}} \quad(i=1 \text { or } 3) \\
& \frac{\phi_{2}}{y_{2}}=\frac{v_{2}}{y_{1} v_{1}+y_{3} v_{3}}
\end{aligned}
$$

The solubility parameter of supercritical carbon dioxide can be calculated by the method proposed by Giddings et al. (1968).

$$
\delta_{1}=1.25 \sqrt{p_{1 \mathrm{C}}} \frac{\rho_{1}{ }^{*}}{\rho_{1}^{\mathrm{L}} *}
$$

where $p_{1 \mathrm{C}}$ is the critical pressure of carbon dioxide. The $\rho_{1}{ }^{*}$ and $\rho_{1}^{\mathrm{L} *}$ are the reduced densities of carbon dioxide at experimental conditions and at liquid state. The value of 
$\rho_{1}{ }^{\mathrm{L}}$ is fixed at 2.66 .

On the other hand, the solubility parameters of solute and entrainer can be estimated by the following equations.

$$
\delta_{i}=\sqrt{\frac{\Delta u_{i}}{v_{i}}}(i=2 \text { or } 3)
$$

where the values of the internal energy change of vaporization for component $i, \Delta u_{i}$ can be calculated by the following equation.

$$
\Delta u_{i}=\Delta u_{i} *\left\{1+1.13 \alpha_{V, i}(T *-T)\right\}^{2}\left\{1-\alpha_{V, i}(T *-T)\right\}
$$

where $T^{*}$ is the standard temperature (=298.15 K), $\Delta u_{i}^{*}$ is the internal energy change of vaporization at $T^{*}$, and $\alpha_{V, i}$ is the isobaric thermal expansivity. The value of $\Delta u_{i}^{*}$ can be calculated by the group contribution method proposed by Fedors (1974). The value of $\alpha_{V, i}$ is fixed at $1.0 \times 10^{-3} \mathrm{~K}^{-1}$ for all solid components as a simplifying.

The molar volume of solute in supercritical fluid phase can be empirically expressed as a function of the density of the supercritical fluids $\rho_{1}$ (Iwai et al., 1992). This leads to:

$\ln v_{2}\left(\mathrm{~m}^{3} \cdot \mathrm{mol}^{-1}\right)=\alpha_{2} \ln \rho_{1}\left(\mathrm{~kg} \cdot \mathrm{m}^{-3}\right)+\beta_{2}$

where the density of supercritical carbon dioxide was calculated with the equation of state of Adachi and Sugie (1986). Other equations of state for carbon dioxide have been proposed by Huang et al. (1985) and Span and Wagner (1996). The coefficients $\alpha_{2}$ and $\beta_{2}$ can be determined by data regression. It is found that $\alpha_{2}$ can be considered to be a constant for homologous solute group such as fatty acids or higher alcohols, and $\beta_{2}$ can be related with the critical volume of the solute. The parameters used in the correlations are listed in Table 3. Figure 6 shows the calculated results for solubilities of fatty acids 
and higher alcohols in supercritical carbon dioxide. The calculated results are in good agreement with the experimental data.

By considering the solvation structure, the entrainer effect on the solubility can be correlated. Eq.(26) can be used to estimate the molar volume of an entrainer in the supercritical carbon dioxide. Through various spectroscopic studies it is known that solute molecules in a supercritical fluid may be apt to cluster with entrainer molecules. The volume occupied by a solute thus can be considered to depend on the local composition of entrainer bound to the solute. A possible approximation for the volume of solute was given by Koga et al. (1996):

$$
\begin{aligned}
& v_{2}=v_{2}^{(1)}+\theta \Delta v_{2} \\
& \Delta v_{2}=v_{2}^{(3)}-v_{2}^{(1)}
\end{aligned}
$$

where $\theta$ is the local composition of entrainer around solute, and $v_{2}{ }^{(1)}$ and $v_{2}{ }^{(3)}$ are the volume of solute in the pure supercritical fluid and in the pure entrainer, respectively. Based on the spectroscopic information (Yonker and Smith, 1988), the local composition can be calculated from the following equation.

$$
\theta=\frac{y_{3}}{\left(p / p^{\text {bulk }}\right)+\left[1-\left(p / p^{\text {bulk }}\right)\right] y_{3}}
$$

where $p^{\text {bulk }}$ means the pressure at the point where the local composition of the entrainer is equal to bulk composition, $y_{3}$. The $\Delta v_{2}$ and $p^{\text {bulk }}$ can be used as adjustable parameters for the calculation of entrainer effects. Figure 7 shows the calculated results of entrainer effect on the solubilities of stearic acid in supercritical carbon dioxide. The parameters are listed in Table 3. The calculated results of entrainer effect on the solubilities are in good agreement with the experimental data. Solution model was applied to correlate the 
solubilities of flavone, 3-hydroxyflavone, and polymers in supercritical carbon dioxide (Uchiyama et al., 1997; Mishima et al., 1998, 1999). Guigard and Stiver (1998) and Stiver et al. (2000) also calculated solubilities by using a solubility parameter.

\subsubsection{Molecular Simulation}

The Henry constant can be written as follows for conditions of infinite dilution (Iwai et al. (1995a)).

$$
H_{2}=\rho_{1} k_{\mathrm{B}} T \exp \left(\frac{\mu_{2}{ }^{\mathrm{r}}}{k_{\mathrm{B}} T}\right)
$$

where $\rho_{1}$ is the number density of the supercritical fluid, $k_{\mathrm{B}}$ is the Boltzmann constant, and $\mu_{2}{ }^{r}$ is the residual chemical potential of the solute. As the solubility in supercritical fluids is usually very small, it can be assumed by the following equation.

$$
y_{2}=f_{2}{ }^{G} / H_{2}
$$

Since the fugacity of solute in the supercritical phase is equal to that of the pure solid phase, the following equation can be derived:

$$
f_{2}{ }^{\mathrm{G}}=f_{2}{ }^{\mathrm{S}}=p_{2}{ }^{\text {sat }} \exp \left[\frac{v_{2}{ }^{\mathrm{S}}\left(p-p_{2}{ }^{\mathrm{sat}}\right)}{R T}\right]
$$

From Eqs.(31) and (32), the solubility in supercritical fluid can be given as follows:

$$
y_{2}=\frac{p_{2}^{\text {sat }}}{H_{2}} \exp \left[\frac{v_{2}{ }^{\mathrm{s}}\left(p-p_{2}{ }^{\mathrm{sat}}\right)}{R T}\right]
$$

For a binary mixture consisting of supercritical fluid and high-boiling compound, the residual chemical potential is given as:

$$
\mu_{2}{ }^{\mathrm{r}}=-k_{\mathrm{B}} T \ln \left\langle\exp \left(-\frac{\psi_{2}}{k_{\mathrm{B}} T}\right)\right\rangle_{N}
$$


where $\psi_{2}$ is the potential energy experienced by a solute placed at a random location in a fluid of $N$ particles of supercritical fluid and $\left\langle>{ }_{N}\right.$ is the canonical ensemble average of the system of $N$ particles. The test particle method proposed by Widom (1963) can be applied to calculate the residual chemical potential of supercritical fluid mixtures.

The Lennard-Jones (12-6) potential function and combining rules are shown as follows:

$$
\begin{aligned}
& \phi_{i j}=4 \varepsilon_{i j}\left[\left(\frac{\sigma_{i j}}{r_{i j}}\right)^{12}-\left(\frac{\sigma_{i j}}{r_{i j}}\right)^{6}\right] \\
& \varepsilon_{12}=\left(1-k_{12}\right)\left(\varepsilon_{11} \varepsilon_{22}\right)^{1 / 2} \\
& \sigma_{12}=\left(1-l_{12}\right)\left(\sigma_{11}+\sigma_{22}\right) / 2
\end{aligned}
$$

In these equations, $\phi$ is the intermolecular potential, $\varepsilon$ and $\sigma$ are the energy and size parameters, $r$ is the molecular distance, $k_{12}$ and $l_{12}$ are the intermolecular interaction parameters between unlike molecules. These relations allow calculation of the solubilities of high-boiling compounds in supercritical carbon dioxide.

The corresponding state principle assures that all Lennard-Jones fluids for pure components obey the same reduced equation of state by using the reduced variables:

$$
\rho^{*}=N \sigma^{3} / V, \quad T^{*}=k_{\mathrm{B}} T / \varepsilon \text { and } p^{*}=\sigma^{3} p / \varepsilon
$$

where $N$ is the number of particles, $V$ the volume of the system, $k_{\mathrm{B}}$ the Boltzmann constant, and superscript * means the reduced property. Equations of state for Lennard-Jones fluid have been reported by Nicolas et al. (1979) and Johnson et al. (1993). Reduced properties proposed by Nicolas et al. (1979) of $\rho_{\mathrm{C}}{ }^{*}, T_{\mathrm{C}} *$, and $p_{\mathrm{C}} *$ at the critical point as $0.35,1.35$, and 0.1418 , respectively. The potential parameters of carbon dioxide and high-boiling compounds can be calculated by using $T_{\mathrm{C}}$ and $p_{\mathrm{C}}$. The $k_{12}$ and 
$l_{12}$ can be adjusted to give good representation of the solubilities in supercritical carbon dioxide. The parameters and properties are listed in Table 4. Figure 8 shows the simulated results of solubilities for naphthalene in supercritical carbon dioxide. As shown in Figure 8, the simulated results of solubilities are in good agreement with the experimental data. The site model potential function can be used for complex solute molecules (Koga et al., 1994; Iwai et al., 1995b, 1996, 2000) and entrainer effects can also be calculated by molecular simulation (Iwai et al., 1994; Koga et al., 1997).

\subsection{Diffusion Coefficient}

\subsubsection{Classifications of Diffusion Coefficient}

According to classification by Reid et al. (1987), diffusion coefficients are classified to the self-diffusion coefficients $\left(D_{11}\right.$ and $\left.D_{22}\right)$, tracer diffusion coefficients $\left(D_{12} *\right.$ and $\left.D_{21} *\right)$, mutual diffusion coefficients $\left(D_{21}\left(=D_{12}\right)\right)$, and infinite dilution diffusion coefficients $\left(D_{12}{ }^{0}\right.$ and $\left.D_{21}{ }^{0}\right)$ as shown in Figure 9. Figure 9 shows the diffusion coefficients for $n$-octane $+n$-dodecane system (Van Geet and Adamson, 1964). Tracer diffusion coefficients which are sometimes referred to as intradiffusion coefficients relate the diffusion of a labeled component within a homogeneous mixture. As well as the mutual diffusion coefficients, tracer diffusion coefficients depend on the composition. As the mole fraction of component 1 approaches unity, $D_{21} *$ and $D_{12} *$ approach $D_{21}{ }^{0}$ and $D_{11}$, respectively. Therefore, for the case of infinite dilution, tracer diffusion coefficients of the solute and supercritical fluid coincide with the mutual and self-diffusion coefficients, respectively.

\subsubsection{At Infinite Dilution Condition}

Most equations for predicting diffusion coefficients in supercritical fluids are applied at infinite dilution conditions in comparison with the actual experimental data 
that can only approach this state. Funazukuri et al. (1991) and Funazukuri (1996) tested various correlations for diffusion coefficients in supercritical carbon dioxide. Liu and Macedo (1995) used a density expansion equation and modified free-volume model. Liu and Ruckenstein (1997a) applied the Stokes-Einstein type equation and Eaton and Akgerman (1997) proposed a predictive equation based on rough hard sphere theory. Thus, many correlation methods for diffusion coefficients in supercritical fluids at infinite dilution were based on a Stokes-Einstein based empirical equation or rough hard sphere theory. In recent works, new predictive expressions have been also proposed (Liu and Ruckenstein, 1997b; Liu et al., 1997; He and Yu, 1997, 1998).

(a) Stokes-Einstein Based Equation

As the order of diffusion coefficients in supercritical fluid is similar to those in liquids, several authors have attempted to correlate diffusion coefficients in supercritical fluids using empirical relations developed for liquid systems. Typical empirical correlation models, such as proposed by Wilke and Chang (1955), Scheibel (1954), Reddy and Doraiswamy (1967), and Lusis and Ratcliff (1968), can be derived from the following Stokes-Einstein expression.

$$
D_{21}^{0}=\frac{k_{\mathrm{B}} T}{6 \pi \mu_{1} R_{0}}
$$

where $k_{\mathrm{B}}$ is the Boltzmann constant, $\mu_{1}$ is the viscosity of supercritical fluid, and $R_{0}$ is the radius of the solute. The applicability of these empirical equations is discussed in the review of Liong et al. (1991a). For example, the calculated results of diffusion coefficients for naphthalene in supercritical carbon dioxide by Wilke-Chang equation are shown in Figure 10. The Wilke-Chang equation is given as follows: 
$D_{21}{ }^{0}=7.4 \times 10^{-11} \frac{T \sqrt{\phi M_{1}}}{\mu_{1} v_{\mathrm{b} 2}{ }^{0.6}}$

where $\phi$ is the association factor ( $\phi=1$ for carbon dioxide), $M_{1}$ is the molecular weight of supercritical carbon dioxide, and $v_{\mathrm{b} 2}$ is the molar volume of solute at boiling point. The values of $M_{1}$ and $v_{\mathrm{b} 2}$ are listed in Table 5. The calculated results show good agreement with the experimental data for diffusion coefficient of naphthalene in supercritical carbon dioxide. However, some modifications are needed for other systems (Sassiat et al., 1987).

(b) Rough Hard Sphere Theory

The rough hard sphere (RHS) theory for transport coefficients of dense fluids can be derived from the model of self-diffusion (Chandler, 1975) and that of mutual diffusion (Bertucci and Flygare, 1975). The validity of RHS theory to the high pressure region was studied by Dymond (1985) and Erkey et al. (1990).

One expression that has been established for self-diffusion is shown as follows (Funazukuri and Wakao, 1995):

$D_{11} \approx D_{11}{ }^{\mathrm{RHS}}=A_{11} D_{11}^{\text {SHS }}$

where

$$
\begin{aligned}
& D_{11}^{\mathrm{SHS}}=C_{\mathrm{S}} D_{11}{ }^{\mathrm{E}} \\
& C_{\mathrm{S}}=\frac{D_{11}^{\mathrm{SHS}}}{D_{11}^{\mathrm{E}}} \\
& D_{11}{ }^{\mathrm{E}}=\frac{3}{8 g_{11}\left(\sigma_{\mathrm{HS}, 1}\right)}\left[\frac{R T}{\pi M_{1}}\right]^{1 / 2} \frac{1}{n \sigma_{\mathrm{HS}, 1}{ }^{2}} \\
& g_{11}\left(\sigma_{\mathrm{HS}, 1}\right)=\frac{1-0.5 \varepsilon}{(1-\varepsilon)^{3}}
\end{aligned}
$$


$\varepsilon=\frac{\pi n \sigma_{\mathrm{HS}, 1}^{3}}{6}$

For mutual diffusion coefficients at infinite dilution conditions, the expressions were developed:

$D_{21}^{0} \approx D_{21}{ }^{\mathrm{RHS}}=A_{21} D_{21}^{\mathrm{SHS}}$

where

$$
\begin{aligned}
& D_{21}{ }^{\mathrm{SHS}}=C_{\mathrm{B}} D_{21}{ }^{\mathrm{E}} \\
& C_{\mathrm{B}}=\frac{D_{21}{ }^{\mathrm{SHS}}}{D_{21}{ }^{\mathrm{E}}}
\end{aligned}
$$

$D_{21}{ }^{\mathrm{E}}=\frac{3}{8 g_{21}\left(\sigma_{\mathrm{HS}, 21}\right)}\left[\frac{R T}{\pi M_{21}}\right]^{1 / 2} \frac{1}{n \sigma_{\mathrm{HS}, 21}{ }^{2}}$

$g_{21}\left(\sigma_{\mathrm{HS}, 21}\right)=\frac{1}{1-\varepsilon}+\frac{3 \varepsilon \gamma}{(1-\varepsilon)^{2}(1+\gamma)}+\frac{\varepsilon^{2} \gamma}{2(1-\varepsilon)^{3}}$

$\varepsilon=\frac{\pi n \sigma_{\mathrm{HS}, 1}^{3}}{6}$

$n=n_{1}+n_{2} \approx n_{1}$

$\sigma_{\mathrm{HS}, 12}=\frac{1}{2}\left(\sigma_{\mathrm{HS}, 1}+\sigma_{\mathrm{HS}, 2}\right)=\frac{\sigma_{\mathrm{HS}, 2}}{2}(\gamma+1)$

$\gamma=\frac{\sigma_{\mathrm{HS}, 2}}{\sigma_{\mathrm{HS}, 1}}$

$$
M_{12}=\frac{2}{\frac{1}{M_{1}}+\frac{1}{M_{2}}}
$$

In Eqs.(41)-(56), RHS, SHS, HS and E refer to rough hard sphere, smoothed hard sphere, hard sphere and Enskog theory. In these equations, $n$ is the number density, and 
$\sigma_{\mathrm{HS}}$ and $M$ are the effective hard sphere diameter and the molecular weight, respectively Funazukuri and Wakao (1995) modified the expressions for self- and mutual diffusion coefficients as follows:

$$
\begin{aligned}
& D_{11}=(A C)_{\mathrm{S}} D_{11}{ }^{\mathrm{E}} \\
& D_{21}{ }^{0}=(A C)_{\mathrm{B}} D_{21}{ }^{\mathrm{E}}
\end{aligned}
$$

where

$$
\begin{aligned}
& (A C)_{\mathrm{S}}=A_{11}\left(D_{11}^{\mathrm{SHS}} / D_{11}^{\mathrm{E}}\right) \\
& (A C)_{\mathrm{B}}=A_{21}\left(D_{21}^{\mathrm{SHS}} / D_{21}^{\mathrm{E}}\right)
\end{aligned}
$$

$A_{11}$ and $A_{21}$ are the translational-rotational coupling parameters which show the deviation from a sphere particle $\left(A_{11}=1\right.$ for sphere particle, $A_{11}<1$ for non-sphere particle). Funazukuri and Wakao (1995) proposed the following empirical equation for diffusivity in supercritical carbon dioxide.

$$
(A C)_{\mathrm{B}}=1.86 \gamma_{\mathrm{vw}}^{0.38}(A C)_{\mathrm{S}}\left(\mathrm{v} / \mathrm{v}_{0}\right)^{-0.447}
$$

where $v$ and $v_{0}$ are the molar volume and hard sphere close-packed molar volume of supercritical carbon dioxide, respectively. The hard sphere close-packed molar volume can be estimated by the following polynomial equation (Funazukuri et al., 1992).

$$
v_{0}=\frac{1}{1.384} \sum_{i=0}^{4} a_{i} T^{i}
$$

where $a_{0}=4.452 \times 10^{-5}, a_{1}=-1.152 \times 10^{-7}, a_{2}=2.749 \times 10^{-10}, a_{3}=-3.073 \times 10^{-13}, a_{4}=1.290 \times 10^{-16}$. The $\gamma_{\mathrm{vw}}$ is the ratio of the van der Waals diameters calculated by Bondi method (1964). $(A C)_{\mathrm{S}}$ is given by the following polynomial equations. 


$$
(A C)_{\mathrm{S}}=\sum_{i=0}^{4} b_{i}\left[\ln \left(v / v_{0}\right)\right]^{i}
$$

where $b_{0}=0.284093, b_{1}=2.55177, b_{2}=-2.26978, b_{3}=0.756249, b_{4}=-0.08903$.

The effective hard-sphere diameter of supercritical carbon dioxide was calculated by

$$
v_{0}=N_{\mathrm{AV}} \sigma_{\mathrm{HS}, 1}{ }^{3} / \sqrt{2}
$$

where $N_{\mathrm{AV}}$ is the Avogadro number and $v_{0}$ can be calculated by Eq.(62). The effective hard-sphere diameter of the solute can be calculated by Eq.(64). The ratio of the hard sphere diameters, $\gamma$, can be replaced by the ratio of van der Waals diameters, $\gamma_{v w}$. The van der Waals diameters are listed in Table 5.

Calculated results for diffusion coefficients of naphthalene in supercritical carbon dioxide by this method are shown in Figure 10. Calculated results for this system and other systems are in good agreement with experimental data (Funazukuri and Wakao, 1995).

(c) Schmidt Number Correlation

The Schmidt number correlation proposed by Funazukuri (2000b) is shown as follows.

$$
\ln \left(S c^{+}-1\right)=\sum_{i=0}^{5} c_{i}\left(\frac{v_{0}}{v}\right)^{i}
$$

where $v$ and $v_{0}$ are the molar volume and the hard sphere closed-packed volume of supercritical carbon dioxide, respectively. The $a_{i}$ are coefficients determined as follows: $c_{0}=-4.92519817, \quad c_{1}=54.5529385, \quad c_{2}=-245.231443, \quad c_{3}=607.893924, \quad c_{4}=-708.884016$, $c_{5}=329.611433$. The $S c^{+}$is defined by

$$
S c^{+}=S c / S c^{*}
$$

where $S c^{*}=5 / 6$ for self-diffusion. For mutual diffusion coefficients at infinite dilution, 
the following equation was proposed:

$$
S C^{*}=\frac{5}{6}\left(\frac{\sigma_{\mathrm{HS}, 1}+\sigma_{\mathrm{HS}, 2}}{2 \sigma_{\mathrm{HS}, 1}}\right)^{2}\left(\frac{2 M_{2}}{M_{1}+M_{2}}\right)^{1 / 2}
$$

The effective hard sphere diameters and the closed-pack molar volume can be obtained by the same method as those used in RHS theory. The density and viscosity of supercritical carbon dioxide, which are necessary to convert the Schmidt number to diffusion coefficient, were calculated by the equations of Angus et al. (1976) and Chung et al. (1988), respectively. New equations for transport properties of carbon dioxide have been proposed by Vesovic et al. (1990) and these equations show the high reliability even at the critical region. The calculated results for diffusion coefficients of naphthalene in supercritical carbon dioxide are shown in Figure 10. The calculated results by the Schmidt number correlation show good agreement with the experimental data.

(d) Molecular Simulation

Molecular dynamics simulation has been used to calculate the self- and tracer diffusion coefficients in supercritical fluid. Katagiri et al. (1993) calculated the diffusion coefficients of naphthalene in supercritical carbon dioxide by MD simulation with the Lennard-Jones potential. They also used the Lorentz-Berthelot mixing rules in spite of the unsymmetrical nature of the system. They pointed out the restriction of the diffusive motion of naphthalene due to the formation of the solvation structure. Inomata et al. (1996) performed the molecular dynamics simulation of infinite dilute solutions of benzene in supercritical carbon dioxide. They reported the solvation structures and translational and rotational diffusion coefficients of benzene in supercritical carbon dioxide. Iwai et al. (1997) and Higashi et al. (1998a) reported the calculated results of 
diffusion coefficients of aromatic compounds in supercritical carbon dioxide by using single-site model molecular dynamics simulations. Kataoka (1998) performed the 2-dimensional molecular dynamics simulation to calculate the mutual diffusion coefficient in the supercritical region and reported anomalous behavior of the diffusion coefficients. De Oliveira et al. (2000) reported the comparison between experimental results and molecular dynamics simulation results of diffusion coefficients. Others of non-equilibrium molecular dynamics simulations have been applied to calculate diffusion coefficients (Wang and Cummings, 1989; Van de ven-Lucassen et al., 1998) in the critical region. It is interesting to apply the non-equilibrium molecular dynamics simulation for direct calculation of mutual diffusion coefficients in the supercritical conditions.

The self-diffusion coefficients of supercritical carbon dioxide and tracer diffusion coefficients of a solute molecule in supercritical carbon dioxide can be calculated by the following two methods. In the first method, the mean square displacement (MSD) of aromatic compound is used and the self-diffusion coefficients of carbon dioxide and tracer diffusion coefficients of a high-boiling compound are calculated by the Einstein relationship:

$$
\begin{aligned}
& D_{11}=\lim _{t \rightarrow \infty} \frac{1}{6 t}\left\langle\left[\mathbf{r}_{1}(t)-\mathbf{r}_{1}(0)\right]^{2}\right\rangle \\
& D_{21} *=\lim _{t \rightarrow \infty} \frac{1}{6 t}\left\langle\left[\mathbf{r}_{2}(t)-\mathbf{r}_{2}(0)\right]^{2}\right\rangle
\end{aligned}
$$

where $\mathbf{r}$ is the position vector of molecules and $t$ is the time.

In the second method, the velocity auto-correlation function (VAF) of a high-boiling compound is used and the self- and tracer diffusion coefficients are calculated by the following equations. 


$$
\begin{aligned}
& D_{11}=\frac{1}{3} \int_{0}^{\infty}\left\langle\mathbf{v}_{1}(t) \cdot \mathbf{v}_{1}(0)\right\rangle \mathrm{d} t \\
& D_{21}^{*}=\frac{1}{3} \int_{0}^{\infty}\left\langle\mathbf{v}_{2}(t) \cdot \mathbf{v}_{2}(0)\right\rangle \mathrm{d} t
\end{aligned}
$$

where $\mathbf{v}$ is the velocity vector of molecules.

The same potential function and combining rules shown in Eqs.(35)-(37) can be used for molecular dynamics simulations of the diffusion coefficients. The intermolecular interaction parameters adjusted to the solubility data can be applied to simulate diffusion coefficients (Higashi et al., 2000). Figure 11 shows simulation results for the diffusion coefficients of carbon dioxide and naphthalene in supercritical carbon dioxide. For this case, the interaction parameters were adjusted to give good correlation of the experimental the solubility data. Calculated results using the RHS theory and the

Schmidt number correlation are also illustrated in Figure 11. Simulation results of diffusion coefficients show good agreement with experimental diffusivity data. However, the anomalous decrease in diffusion coefficients near the critical point cannot be represented by this method as well as other methods that use the infinite dilution state.

\subsubsection{Concentration Dependence}

Correlation equations for the diffusivity in liquids have been adopted to investigate their applicability to represent the concentration dependence of diffusion coefficients in supercritical fluids. The anomalies of diffusion coefficients near the critical point are represented by their equations (Clifford and Coleby, 1991; Bartle et al., 1991a; Dysthe and Hafskjold, 1995; Nishiumi et al., 1996; Ago and Nishiumi, 1998).

The correlation equation developed by Darken (1948) to represent the concentration dependence for mutual diffusion coefficient at finite concentration is given as: 


$$
D_{21}=\left(y_{2} D_{11} *+y_{1} D_{21} *\right) \alpha
$$

where $y$ and $D^{*}$ are the mole fraction and tracer diffusion coefficient, respectively. In Eq.(72), $\alpha$ is the thermodynamic factor that is calculated according to the following expression:

$\alpha=\left(\frac{\partial \ln f_{2}}{\partial \ln y_{2}}\right)$

where $f_{2}$ is the fugacity of the solute.

As the solubility of naphthalene in supercritical carbon dioxide is the order of $10^{-3}$ and the concentration dependence of tracer diffusion coefficient is very small, the concentration dependent diffusion coefficients can be represented by

$$
D_{21}=\left(y_{2} D_{11}+y_{1} D_{21}{ }^{0}\right)\left(\frac{\partial \ln f_{2}}{\partial \ln y_{2}}\right)
$$

where $D_{11}$ and $D_{21}{ }^{0}$ are the self-diffusion coefficient of supercritical carbon dioxide and the infinite dilution diffusion coefficient of solute, respectively.

Higashi et al. (1999) applied the Darken equation for the correlation of the mass-fixed diffusion coefficients, $D_{2}$, of naphthalene in supercritical carbon dioxide. The relationship between the mutual diffusion coefficient and the mass-fixed diffusion coefficient are presented by the following expression (Hartlay and Crank, 1949; Fitts, 1962):

$$
D_{2}=\frac{D_{21}}{C \bar{v}_{1}}
$$

where $C$ is the molar density of carbon dioxide containing solute and $\bar{v}_{1}$ denoted the partial molar volume of carbon dioxide.

In their correlation, the molar density, the partial molar volume, and the fugacity 
was calculated by the Iwai-Margerum-Lu (IML) equation of state (Iwai et al., 1988) and the mole fraction of solute, $y_{2}$, was approximated by the saturated solubility devided by two, $y_{2}{ }^{\text {sat }} / 2$. Mixing and combining rules are given by Eqs.(12)-(14). The $k_{i j}$ and $l_{i j}$ were adjusted to fit the solubility data, and this allowed the anomalous decrease and concentration dependence of the diffusion coefficients to be decreased by the Darken equation and the IML equation of state as shown in Figure 10.

Tuan et al. (1999c) applied the Leffler and Cullinan equation (1970) for the calculation of the concentration dependence of diffusion coefficient of lipid in supercritical carbon dioxide. Their equation is shown as follows.

$$
D_{21}=\left\{\left(\mu_{1} D_{21}{ }^{0}\right)^{y_{1}}+\left(\mu_{2} D_{12}{ }^{0}\right)^{y_{2}}\right\} \frac{1}{\mu} \alpha
$$

where $\mu i$ is the velocity of each component and $\mu$ denoted that of mixture.

They applied the Peng-Robinson (PR) equation of state (Peng and Robinson, 1976) to calculate the thermodynamic factor $\alpha$, and only a single binary interaction parameter, $k_{i j}$, was used in the mixing and combining rules. The values of diffusion coefficients of methyl oleate and carbon dioxide at infinite dilution were estimated by the method of Liong et al. (1991b) and that of Wilke and Chang (1955), respectively. Viscosities of carbon dioxide were interpolated from the tabulated values available in the literature (Stephan and Lucas, 1979). The viscosity of methyl oleate was estimated by the methods of Kashulines et al. (1991). The viscosity of the mixture was estimated by the Ely and Hanley corresponding state method (Tuan et al., 1999b). The calculated diffusion coefficients were corrected by the following equation:

$$
D_{21, \text { corr. }}=D_{21}+\frac{y_{2}}{y_{2}^{\text {sat }}} D_{21}^{\text {sat }}
$$


The correlation results by Tuan et al. for the concentration dependence of diffusion coefficients of methyl oleate in supercritical carbon dioxide at $313.2 \mathrm{~K}$ are shown in Figure 12. The correlation results show good agreement with the experimental results.

\section{Conclusion}

The application of empirical equations, equation of state, solution models, and Monte Carlo simulation for the calculation of solubilities of high-boiling compounds in supercritical carbon dioxide were reviewed. For simple convenience of the usage, empirical equations can be used to investigate consistency of solubility data for design of a supercritical extraction process. Correlation methods using equation of state and solution model can be used to estimate solubilities and entrainer effects in supercritical fluids. When the critical properties, the vapor pressure, and the solid molar volume of the solute are unknown, solution model may be more useful because it needs only the melting point and the heat of fusion.

The applications of empirical equation based on the Stokes-Einstein model, the rough hard sphere theory, the Schmidt number correlation, and molecular dynamics simulation for the calculation of diffusion coefficients in supercritical carbon dioxide at infinite dilution condition are reviewed. Further, the application of the Darken equation and the Leffler and Cullinan equation are reviewed to calculate the concentration dependence of diffusion coefficients. Modification of empirical equations will be needed to correlate diffusion coefficients in supercritical fluids. The rough hard sphere theory and the Schmidt number correlation can be used to estimate diffusion coefficients in supercritical carbon dioxide. Concentration dependence of diffusion coefficients in supercritical carbon dioxide can be evaluated by the equation for diffusivity in liquids. 
Molecular simulation can be used to calculate the solubility and diffusion coefficient in supercritical fluids. Not only properties such as solubility and diffusion coefficient, but also solvation structure and molecular interaction can be obtained by molecular simulation. Molecular simulation has become an available technique to investigate the characteristics of supercritical fluids. 


\section{Literature Cited.}

Adachi Y., \& Sugie H. (1986). Development of a five-parameter cubic equation of state. Fluid Phase Equilibria, 28, 119-136.

Ago K., \& Nishiumi H. (1998). Calculation of mutual diffusion coefficients near the critical region from the Peng-Robinson equation of state. Ind.Eng.Chem.Res., 37(5), 1692-1695.

Akgerman A., Erkey C., \& Orejuela M. (1996). Limitting diffusion coefficients of heavy molecular weight organic contaminants in supercritical carbon dioxide. Ind.Eng.Chem.Res., 35(3), 911-917.

Angus S., Armstrong B., \& de Reuck K. M. (1976). Carbon Dioxide; International Tables of the Fluid State-3. New York: Pergamon Press.

Anitescu G., \& Tavlarides L. L. (1999). Solubility of individual polychlorinated biphenyl (PCB) congeners in supercritical fluids: $\mathrm{CO}_{2}, \mathrm{CO}_{2} / \mathrm{MeOH}$ and $\mathrm{CO}_{2} / n-\mathrm{C}_{4} \mathrm{H}_{10}$. J.Supercritical Fluids, 14(3), 197-211.

Aris R. (1956). On the dispersion of solute in a fluid flowing through a tube. Proc.Roy.Soc.Lond.A, 235,67-77.

Bartle K. D., Baulch D. L., Clifford A. A., \& Coleby S. E. (1991a). Magnitude of the diffusion coefficient anomaly in the critical region and its effect on supercritical fluid chromatography. J. Chromatography, 557,69-83.

Bartle K. D., Clifford A. A., Jafar S. A., \& Shilstone G. F. (1991b). Solubilities of solids and liquids of low volatility in supercritical carbon dioxide. J.Phys.Chem.Ref.Data, 20(4), 713-756.

Bertucci S. J., \& Flygare W. H. (1975). Rough hard sphere treatment of diffusion in binary liquid mixtures. J.Chem.Phys., 63(1), 1-9. 
Bondi A. (1964). van der Waals volumes and radii. J.Phys.Chem., 68(3), 441-451.

Bruno T. J., \& Ely J. F. (1991). Supercritical Fluid Technology: Reviews in modern theory and applications, Boca Raton: CRC Press.

Chandler D. (1975). Rough hard sphere theory of the self-diffusion constant for molecular liquids. J.Chem.Phys., 62(4), 1358-1363.

Charpentier B. A., \& Sevenants M. R. (1988). Supercritical Fluid Extraction and Chromatography: Techniques and Applications, ACS Symposium Series 366.

Chen J. -W., \& Tsai F. -N. (1995).Solubilities of methoxybenzoic acid isomers in supercritical carbon dioxide. Fluid Phase Equilibria, 107(2), 189-200.

Chrastil J. (1982). Solubility of solids and liquids in supercritical gases. J.Phys.Chem., 86(15), 3016-3021.

Chung S. T., \& Shing K. S. (1992). Multiphase behavior of binary and ternary systems of heavy aromatic hydrocarbons with supercritical carbon dioxide. Part I. Experimentals results. Fluid Phase Equilibria, 81(2), 321-341.

Chung T.-H., Ajlan M., Lee L.L., \& Starling K.E. (1988). Generalized multiparameter correlation for nonpolar and polar fluid transport properties. Ind. Eng. Chem. Res., 27(4), 671-679.

Clifford A. A., \& Coleby S. E. (1991). Diffusion of a solute in dilute solusion in a supercritical fluid. Proc.Roy.Soc.Lond.A, 433, 63-79.

Clifford T. (1999). Fundamentals of Supercritical Fluids, New York: Oxford University Press.

Czubryt J. J., Myers M. N., \& Giddings J. C. (1970). Solubility phenomena in dense carbon dioxide gas in the range 270-1900 atmospheres. J.Phys.Chem., 74(24), 
4260-4266.

Darken L.S. (1948). Diffusion, mobility and their interrelation through free energy in binary metallic systems. Trans. Am. Inst. Min. Metall. Eng., 175, 184.

De Oliveria J. V., Tavares F. W., Yang X. N., Coellho L. A. F., \& Matthews M. A. (2000). Role of attractive forces in self-diffusion and mutual diffusion in dense simple fluids and real substances. Proc.5th.Int.Symp.Supercritical Fluids, Atlanta.

Deiters U. K., \& Schneider G. M. (1986). High pressure phase equilibria: experimental methods. Fluid Phase Equilibria, 29, 145-160.

Dobbs J. M., Wong J. M., Lahiere R. J., \& Johnston K. P. (1987). Modification of supercritical fluid phase behavior using polar cosolvents. Ind.Eng.Chem.Res., 26(1), 56-65.

Dohrn R., \& Brunner G. (1995). High pressure fluid phase equilibria: experimental methods and systems investigated (1988-1993). Fluid Phase Equilibria, 106, 213-282. Dymond J. H. (1985). Hard-sphere theories of transport properties. Chem.Soc.Rev., 14, 317-356.

Dysthe D. K., \& Hafskjold B. (1995). Inter- and intradiffusion in liquid mixtures of methane and n-decane. Int.J.Thermophysics, 16(5), 1213-1224.

Eaton A. P., \& Akgerman A. (1997). Infinite-dilution diffusion coefficients in supercritical fluids. Ind.Eng.Chem.Res., 36(3), 923-931.

Erkey C. (2000). Supercritical carbon dioxide extraction of metals from aqueous solutions: a review. J.Supercritical Fluids, 17, 259-287.

Erkey C., Gadara H., \& Akgerman A. (1990). Application of rough hard sphere theory to diffusion in supercritical fluids. J.Supercritical Fluids, 3,180-185.

Fedors R. F. (1974). Method for estimating both the solubility parameters and molar 
volumes of liquids. Polym.Eng.Sci., 14(2), 147-154.

Fitts D. D. (1962). Nonequilibrium Thermodynamics, New York, McGraw-Hill.

Flory P. J. (1942). Thermodynamics of high polymer solutions. J.Chem.Phys., 10(1), 51-61.

Fornari R.E., Alessi P., \& Kikic I. (1990). High pressure fluid phase equilibria: experimental methods and systems investigated (1978-1987). Fluid Phase Equilibria, $57,1-33$.

Funazukuri T. (1996). Binary diffusion coefficients of organic compounds in supercritical fluids. Rev.High Pressure Sci.Technol., 5(1), 34-41.

Funazukuri T., Hachisu S., \& Wakao N. (1991). Measurements of binary diffusion coefficients of $\mathrm{C}_{16}-\mathrm{C}_{24}$ unsaturated fatty acid methyl esters in supercritical carbon dioxide. Ind.Eng.Chem.Res., 30(6),1323-1329.

Funazukuri T., Ishiwata Y., \& Wakao N. (1992). Predictive correlation for binary

diffusion coefficients in dense carbon dioxide. AIChE J., 38(11), 1761-1768.

Funazukuri T., Kong C. Y., \& Kagei S. (2000a). On the measurement of anomalous binary diffusion coefficients in the near-critical region. Ind.Eng.Chem.Res., 39(3), 835-837.

Funazukuri T., Kong C. Y., \& Kagei S. (2000b). Binary diffusion coefficients of acetone in carbon dioxide at 308.2 and $313.2 \mathrm{~K}$ in the pressure range from 7.9 to $40 \mathrm{MPa}$. Int.J.Thermophys., 21(3), 651-669.

Funazukuri T., \& Wakao N. (1995). Application of rough hard sphere model to binary diffusion coefficients of organic compounds in dense $\mathrm{CO}_{2}$. Kagaku Kougaku Ronbunshu, 21(1), 204-211.

Furuya T., \& Teja A. S. (2000). Krichevskii parameters and the solubility of heavy 
n-alkanes in supercritical carbon dioxide. Proc.5th.Int.Symp.Supercritical Fluids, Atlanta.

Giddings J. C., Myer M. N., McLaren L., \& Keller R. A. (1968). High pressure gas chromatography of nonvolatile species. Science, 162, 67-73.

Gordillo M. D., Blanco M. A., Molero A., \& de la Ossa E. M. (1999). Solubility of the antibiotic Penicillin G in supercritical carbon dioxide. J.Supercritical Fluids, 15(3), 183-190.

Guan B., Liu Z., Han B., \& Yan H. (1999). Solubility of behenic acid in supercritical carbon dioxide with ethanol. J.Supercritical Fluids, 14(2), 213-218.

Guclu-Ustundag and Temelli (2000). Solubility behavior of fatty acids, mono-, di-, triglycerides and fatty acid esters in supercritical carbon dioxide. Proc.5th.Int.Symp.Supercritical Fluids, Atlanta.

Guigard S. E., \& Stiver W. H. (1998). A density-dependent solute solubility parameter for correlating solubilities in supercritical fluids. Ind.Eng.Chem.Res., 37(9), 3786-3792. Hartlay G. S., \& Crank J. (1949). Some fundamental definitions and concepts in diffusion processes. Trans.Faraday Soc., 45, 801-818.

He C. -H., \& Yu Y. -S. (1997). Estimation of infinite-dilution diffusion coefficients in supercritical fluids. Ind.Eng.Chem.Res., 36(10), 4430-4433.

He C. -H., \& Yu Y. -S. (1998). New equation for infinite-dilution diffusion coefficients in supercritical and high-temperature liquid solvent. Ind.Eng.Chem.Res., 37(9), 3793-3798.

Higashi H., Iwai Y., Uchida H., \& Arai Y. (1998a) Diffusion coefficients of aromatic compounds in supercritical carbon dioxide using molecular dynamics simulation. J.Supercritical Fluid, 13, 93-97. 
Higashi H., Iwai Y., Takahashi Y., Uchida H., \& Arai Y. (1998b) Diffusion coefficients for naphthalene and dimethylnaphthalene in supercritical carbon dioxide. Fluid Phase Equilibria, 144, 269-278.

Higashi H., Iwai Y., Nakamura Y., Yamamoto S., \& Arai Y. (1999) Correlation of diffusion coefficients for naphthalene and dimethylnaphthalene isomers in supercritical carbon dioxide. Fluid Phase Equilibria, 166, 101-110.

Higashi H. Iwai Y., \& Arai Y. (2000) Calculation of self-diffusion and tracer diffusion coefficients near the critical point of carbon dioxide using molecular dynamics simulation. Ind.Eng.Chem.Res., in press.

Hildebrand J. H., Prausnitz J. M., \& Scott R. C. (1970). Regular and Related Solutions: The solubility of gases, liquids, and solids, New York: Van Nostrand Reinhold Company.

Holderbaum T., Gmehling J. (1991). PSRK - A group contribution equation of state based on UNIFAC. Fluid Phase Equilibria, 70(2-3), 251-265.

Huang F. -H., Li M. -H., Lee L. L., Starling K. E., \& Chung F. T. H. (1985). An accurate equation of state for carbon dioxide. J.Chem.Eng.Japan, 18(6), 490-496.

Hutchenson K. W., \& Foster N. R. (1995). Innovations in Supercritical Fluids: Science and Technology, ACS Symposium Series 608.

Inomata H., Saito S., \& Debenedetti P. G. (1996). Molecular dynamics simulation of infinitely dilute solutions of benzene in supercritical $\mathrm{CO}_{2}$. Fluid Phase Equilibria, 116, 282-288.

Iomtev M. B., \& Tsekhanskaya Y. V. (1964). Diffusion of naphthalene in compressed ethylene and carbon dioxide. Russ.J.Phys.Chem., 38(4), 485-487. 
Iwai Y., Fukuda T., Koga Y., \& Arai Y. (1991). Solubilities of myristic acid, palmitic acid, and cetyl alcohol in supercritical carbon dioxide at $35{ }^{\circ}$ C. J.Chem.Eng.Data, 36, 430-432.

Iwai Y., Higashi H., Uchida H., \& Arai Y. (1997). Molecular dynamics simulation of diffusion coefficients of naphthalene and 2-naphthol in supercritical carbon dioxide. Fluid Phase Equilibria, 127, 251-261.

Iwai Y., Koga Y., Fukuda T., \& Arai Y. (1992). Correlation of solubilities of high-boiling compounds in supercritical carbon dioxide using a solution model. J.Chem.Eng.Japan, 25(6), 757-760.

Iwai Y., Koga Y., Maruyama H., \& Arai Y. (1993a). Solubilities of stearic acid, stearyl alcohol, and arachidyl alcohol in supercritical carbon dioxide at $35{ }^{\circ} \mathrm{C}$.

J.Chem.Eng.Data, 38, 506-508.

Iwai Y., Koga Y., Hata Y., Uchida H., \& Arai Y. (1995a). Monte Carlo simulation of solubilities of naphthalene in supercritical carbon dioxide. Fluid Phase Equilibria, 104,403-412.

Iwai Y. Lu B. C. -Y., Yamamoto H., \& Arai Y. (1989). Correlation of solubilities in supercritical fluids and entrainer effect using equation of state -Examination of mixing rules-. Kagaku Kougaku Ronbunshu, 15(3), 676-681.

Iwai Y., Margerum M.R., Lu B.C.-Y. (1988). A new three-parameter cubic equation of state for polar fluids and fluid mixture. Fluid Phase Equilibria, 42, 21-41.

Iwai Y., Mori Y., Hosotani N., Higashi H., Furuya T., Arai Y., Yamamoto K., \& Mito Y. (1993b). Solubilities of 2,6 -and 2,7- dimethylnaphthalenes in supercritical carbon dioxide. J.Chem.Eng.Data, 38, 509-511. 
Iwai Y., Mori Y., Koga Y., Arai Y., \& Eya H. (1994). Monte Carlo calculation of solubilities of high-boiling component in supercritical carbon dioxide and solubility enhancements by entrainer. J.Chem.Eng.Japan, 27(3), 334-339.

Iwai Y., Mori Y., \& Arai Y. (2000). Monte Carlo simulation for solubilities of polycyclic aromatic hydrocarbons in supercritical carbon dioxide Lennard-Jones potentials for supercritical carbon dioxide + polycyclic aromatic hydrocarbon systems from benzene to graphite. Fluid Phase Equilibria, 167, 33-40.

Iwai Y., Uchida H., Koga Y., Mori Y., \& Arai Y. (1995b). Monte Carlo simulation of solubilities of aromatic compounds in supercritical carbon dioxide. Fluid Phase Equilibria, 111, 1-13.

Iwai Y., Uchida H., Koga Y., Arai Y., \& Mori Y. (1996). Monte Carlo simulation of solubilities of aromatic compounds in supercritical carbon dioxide by a group contribution site model. Ind.Eng.Chem.Res., 35(10), 3782-3787.

Johnston K. P., \& Penninger J. M. L. (1989). Supercritical Fluid Science and Technology, ACS Symposium Series 329.

Kashulines P., Rizvi S. S. H., Harriott P., \& Zollweg J. A. (1991). Viscosities of fatty acids and methylated fatty acids saturated with supercritical carbon dioxide. J.Am.Oil Chem.Soc., 68(12), 912-921.

Katagiri, M., Matsumoto, S., \& Tanaka, M., (1993). MD simulation of short-range order among molecules in supercritical dilute solution: Solvation structure around solute molecule. In M. Doyama, J. Kihara, M. Tanaka and R. Yamamoto, Computer aided innovation of new materials II (pp.279-282). Amsterdam: Elsevier.

Kataoka Y. (1998). Anomalous in the concentration fluctuations and the mutual diffusion coefficient of 2-dimensional Lennard-Jones mixture in the supercritical region. 
Fluid Phase Equilibria, 144,257-267.

Kawakami T., Saito N., Ikushima Y., Liew C. C., Aiba K., \& Ohkawa T. (2000).

Highly-soluble fluorocarbon surfactant in supercritical carbon dioxide: Effect of counter cation on solubility. Chemistry Letters, 4, 402-403.

King J.W., \& List G. R. (1996). Supercritical fluid technology in oil and lipid chemistry, Champaign: AOCS Press.

Knaff G., \& Schlünder E. U. (1987). Diffusion coefficients of naphthalene and caffeine in supercritical carbon dioxide. Chem.Eng.Process, 21, 101-105.

Koga Y., Iwai Y., \& Arai Y. (1994). Monte Carlo simulation for chain molecules in supercritical ethane. J.Chem.Phys., 101(3), 2283-2288.

Koga Y., Iwai Y., Hata Y., Yamamoto M., \& Arai Y. (1996). Influence of cosolvent on solubilities of fatty acids and higher alcohols in supercritical carbon dioxide. Fluid Phase Equilibria, 125, 115-128.

Koga Y., Iwai Y., Yamamoto M., \& Arai Y. (1997). Monte Carlo simulation for solubility and spatial structure of fatty acid and higher alcohol in supercritical carbon dioxide with octane. Fluid Phase Equilibria, 131, 83-96.

Kramer A., \& Thodos G. (1988). Adaptation of the Flory-Huggins theory for modeling supercritical solubilities of solids. J.Chem.Eng.Data, 27, 1506-1510.

Kurnik R. T., Holla S. J., \& Reid R. C. (1981). Solubility of solids in supercritical carbon dioxide and ethylene. J.Chem.Eng.Data, 26, 47-51.

Lamb D. M., Adamy S. T., Woo K. W., \& Jonas J. (1989). Transport and relaxation of naphthalene in supercritical fluids. J.Phys.Chem., 93(2), 5002-5005.

Lee J. W., Min J. M., \& Bae H. K. (1999). Solubility measurement of disperse dyes in supercritical carbon dioxide. J.Chem.Eng.Data, 44(4), 684-687. 
Leffler J., \& Cullinan H. T. (1970). Variation of liquid diffusion coefficients with composition (Binary systems). Ind.Eng.Chem.Res., 9(1), 84-88.

Liong K. K., Wells P. A., \& Foster N. R. (1991a). Diffusion in supercritical fluids. J.Supercritical Fluids, 4(2), 91-108.

Liong K. K., Wells P. A., \& Foster N. R. (1991b). Diffusion coefficients of long-chain esters in supercritical carbon dioxide. Ind.Eng.Chem.Res., 30(6), 1329-1335.

Liu H., \& Macedo E. A. (1995). Accurate correlations for the self-diffusion coefficients of $\mathrm{CO}_{2}, \mathrm{CH}_{4}, \mathrm{C}_{2} \mathrm{H}_{4}, \mathrm{H}_{2} \mathrm{O}$, and $\mathrm{D}_{2} \mathrm{O}$ over wide ranges of temperature and pressure. J.Supercritical Fluids, 8(4), 310-317.

Liu H., \& Ruckenstein E. (1997a). Predicting the diffusion coefficients in supercritical fluids. Ind.Eng.Chem.Res., 36(3), 888-895.

Liu H., \& Ruckenstein E. (1997b). A predictive equation for the tracer diffusion coefficients of various solutes in gases, supercritical fluids, and liquids. Ind.Eng.Chem.Res., 36(12), 5488-5500.

Liu H., Silva C. M., \& Macedo E. A. (1997). New equation for tracer diffusion coefficients of solute in supercritical and liquid solvents based on the Lennard-Jones fluid model. Ind.Eng.Chem.Res., 36(1), 246-252.

Lucien F. P., \& Foster N. R. (2000). Solubilities of solid mixtures in supercritical carbon dioxide: A Review. J.Supercritical Fluid, 17, 111-134.

Lusis M. A., \& Ratcliff G. A. (1968). Diffusion in bynary liquid mixtures at infinite dilution. Can.J.Chem.Eng., 46, 385-387.

McHugh M., \& Paulaitis M. E. (1980). Solid solubility of naphthalene and biphenyl in supercritical carbon dioxide. J.Chem.Eng.Data, 25(4), 326-329.

Mendez-Santiago J., \& Teja A. S. (1999). The solubility of solids in supercritical fluids. 
Fluid Phase Equilibria, 160, 501-510.

Mendez-Santiago J., \& Teja A. S. (2000). Solubility of solids in supercritical fluids:

Consistency of data for design of separation equipment. Proc.5th.Int.Symp.Supercritical Fluids, Atlanta.

Mishima K., Matsuyama K., \& Nagatani M. (1999). Solubilities of poly(ethylene glycol)s in the mixtures of supercritical carbon dioxide and cosolvent. Fluid Phase Equilibria, 161(2), 315-324.

Mishima K., Tokuyasu T., Matsuyama K., Komorita N., Enjoji T., \& Nagatani M. (1998). Solubility of polymer in the mixtures containing supercritical carbon dioxide and antisolvent. Fluid Phase Equilibria, 144(1-2), 299-305.

Mochizuki S., Wada N., Smith R. L., \& Inomata H. (1999). Perfluorocarboxylic acid counter ion enhanced extraction of aqueous alkali metal ions with supercritical carbon dioxide. Analyst, 124(10), 1507-1511.

Muthukumaran P, Gupta R. B., Sung H. D., Shim J. J., \& Bae H. K. (1999). Dye solubility in supercritical carbon dioxide. Effect of hydrogen bonding with cosolvents. Korean J.Chem.Eng., 16(1), 111-117.

Nicolas, J.J., Gubbins, K.E., Streett, W.B., \& Tildesley, D.J. (1979). Equation of state for the Lennard-Jones fluid. Mol. Phys., 37, 1429-1454.

Nishiumi H., Fujita M., \& Agou K. (1996). Diffusion of acetone in supercritical carbon dioxide. Fluid Phase Equilibria, 117(1-2), 356-363.

O'hern Jr. H. A., \& Martin J. J. (1955). Diffusion in carbon dioxide at elevated pressures. Ind.Eng.Chem., 47(10), 2081-2086.

Özel M. Z., Bartle K. D., Clifford A. A., \& Burford M. D. (2000). Extraction, solubility and stability of metal complexes using stainless steel supercritical fluid extraction 
system. Anal.Chem.Acta, 417, 177-184.

Paulaitis M. E., Penninger J. M. L., Gray Jr. R.D., \& Davidson P. (1983). Chemical Engineering at Supercritical Fluid Conditions, Michigan: Ann Arbor Science.

Peng D. Y., \& Robinson D. B. (1976). A new two-constant equation of state. Ind.Eng.Chem.Fundam., 15, 59-64.

Quiram D. J., Oconnell J. P., \& Cochran H. D. (1994). The solubility of solids in compressed gases. J.Supercritical Fluids, 7(3), 159-164.

Reid B. C., Prausnitz J. M. \& Poling B. E. (1987). The Properties of Gases and Liquids, 4th edn., New York: McGraw-Hill.

Reddy K. A., \& Doraiswamy L. K. (1967). Estimating liquid diffusivity. Ind.Eng.Chem.Fundam., 6(1), 77-79.

Saito S. (1995). Research activities on supercritical fluid science and technology in Japan - A review. J.Supercritical Fluids, 8(3), 177-204.

Sassiat P. R., Mourier P., Caude M. H., \& Rosset R. H. (1987). Measurement of diffusion coefficients in supercritical carbon dioxide and correlation with the equation of Wilke and Chang. Anal.Chem., 59,1164-1170.

Scheibel E. G. (1954). Liquid diffusivities. Ind.Eng.Chem., 46(9), 2007-2008.

Schmitt W. J., \& Reid R. C. (1985). The influence of the solvent gas on solubility and selectivity in supercritical extraction. In J. M. L. Penninger, M. Radosz, M. A. McHugh \& V. J. Krukonis, Supercritical Fluid Technology (pp.123-147). Amsterdam: Elsevier. Smith R. M., \& Hawthorne S. B. (1997). Supercritical Fluids in Chromatography and Extraction, Amsterdam: Elsevier.

Soave G. (1972). Equilibrium constants from a modified Redlich-Kwong equation of state. Chem.Eng.Sci., 27, 1197-1203. 
Span R., \& Wagner W. (1996). A new equation of state for carbon dioxide covering the fluid region from the triple-point temperature to $1100 \mathrm{~K}$ at pressures up to $800 \mathrm{MPa}$. J.Phys.Chem.Ref.Data, 25(6), 1509-1596.

Squires T. G., \& Paulaitis M.E. (1987). Supercritical Fluids, ACS Symposium Series 329.

Stahl E., Schilz W., Schütz E., \& Willing E. (1978). A quick method for the microanalytical evaluation of the dissolving power of supercritical gases. Angew.Chem.Int.Ed.Eng., 17, 731-738.

Stephan K., \& Lucas K. (1979). Viscosity of Dense Fluids, New York: Plenum Press.

Stiver W. H., Guigard S. E., \& Beausoleil P. (2000). Predicting ternary solubilities using a solubility parameter. Proc.5th.Int.Symp.Supercritical Fluids, Atlanta.

Suarez J. J., Medina I., \& Bueno J. L. (1998). Diffusion coefficients in supercritical fluids: Available data and graphic correlations. Fluid Phase Equilibria, 153,167-212. Sung H. D., \& Shim J. J. (1999). Solubility of C. I. disperse red 60 and C. I. disperse blue 60 in supercritical carbon dioxide. J.Chem.Eng.Data, 44(5), 985-989.

Taylor G. (1953). Dispersion of soluble matter in solvent flowing slowly through a tube. Proc.Roy.Soc.Lond.A, 219, 186-203.

Taylor G. (1954). Conditions under which dispersion of a stream of solvent can be used to measure molecular diffusion. Proc.Roy.Soc.Lond.A, 225, 473-477.

Tochigi K. (1995). Prediction of high-pressure vapor-liquid-equilibria using ASOG. Fluid Phase Equilibria, 104, 253-260.

Tochigi K., Iizumi T., Sekikawa H., Kurihara K., \& Kojima K. (1998). High-pressure vapor-liquid and solid-gas equilibria using a Peng-Robinson group contribution method. Ind.Eng.Chem.Res., 37(9), 3731-3740. 
Trabelsi F., Abaroudi K., \& Recasens F. (1999). Predicting the approximate solubilities of solids in dense carbon dioxide. J.Supercritical Fluids, 14(2), 151-161.

Tsekhanskaya Y. V. (1971). Diffusion of naphthalene in carbon dioxide near the liquid-gas critical point. Russ.J.Phys.Chem., 45(5), 744.

Tsekhanskaya Y. V., Iomtev M. B., \& Mushkina E. V. (1964). Solubility of naphthalene in ethylene and carbon dioxide under pressure. Russ.J.Phys.Chem., 38(9), 1173-1176.

Tuan D. Q., Yener M. E., Zollweg J. A., Harriott P., \& Rizvi S. S. H. (1999a).

Steady-state parallel plate apparatus for measurement of diffusion coefficient in supercritical carbon dioxide. Ind.Eng.Chem.Res., 38(2), 554-561.

Tuan D. Q., Zollweg J. A., \& Rizvi S. S. H. (1999b). Measurement and modeling of viscosity of supercritical carbon dioxide/biomaterial(s) mixture. Ind.Eng.Chem.Res., 38(7), 2129-2136.

Tuan D. Q., Zollweg J. A., \& Rizvi S. S. H. (1999c). Concentration dependence of the diffusion coefficient of lipid in supercritical carbon dioxide. Ind.Eng.Chem.Res., 38(7), 2787-2793.

Uchiyama H., Mishima K., Oka S., Ezawa M., Ide M., Takai T., \& Park P. W. (1997).

Solubilities of flavone and 3-hydroxyflavone in supercritical carbon dioxide.

J.Chem.Eng.Data, 42(3), 570-573.

Van de ven-Lucassen I. M. J. J., Vlugt T. J. H., van der Zanden A. J. J., \& Herkhof P. J. A. M. (1998). Using molecular dynamics to obtain Maxwell-Stefan diffusion coefficients in liquid system. Mol.Phys., 94(3), 495-503.

Van Geet A. L. \& Adamson A. W. (1964). Diffusion in liquid hydrocarbon mixtures. J.Phys.Chem., 68(2), 238-246.

Vesovic V., Wakeham W. A., Olchowy G. A., Sengers J. V., Watson J. T. R. \& Millat J. 
(1990). The transport properties of carbon dioxide. J.Phys.Chem.Ref.Data, 19(3), 763-808.

Wagner B., Kautz C. B., \& Schneider G. M. (1999). Investigations on the solubility of anthraquinone dyes in supercritical carbon dioxide by a flow methods. Fluid Phase Equilibria, 160, 707-712.

Wang B. Y., \& Cummings P. T. (1989). Non-equilibrium molecular dynamics calculation of the transport properties of carbon dioxide. Fluid Phase Equilibria, 53, 191-198.

Widom B. (1963). Some topics in the theory of fluids. J.Chem.Phys., 39, 2808-2812. Wilke C. R., \& Chang P. (1955). Correlation of diffusion coefficients in dilute solutions. AIChE J., 1(2), 264-270.

Yamamoto M., Iwai Y., Nakajima T., Tanabe D., \& Arai Y. (2000). Correlation of solubilities and entrainer effects for fatty acids and higher alcohols in supercritical carbon dioxide using SRK equation of state with association model. J.Chem.Eng.Japan, 33(3), 538-544.

Yonker C. R., \& Smith R. D. (1988). Solvatochromic behavior of binary supercritical fluids: The carbon dioxide/2-propanol system. J.Phys.Chem., 92(8), 2374-2378.

Yu L. M., \& Lu B. C. -Y. (1987a). A three-parameter cubic equation of state for asymmetric mixture density calculations. Fluid Phase Equilibria, 34, 1-19.

Yu L. M., Lu B. C. -Y., \& Iwai Y. (1987b). Simultanious calculations of VLE and standerd liquid and vapor volumes by means of a 3P1T cubic EOS. Fluid Phase Equilibria, 37, 207-222. 